\title{
Idiopathic Right Bundle Branch Block by ECG Finding
}

National Cancer Institute

\section{Source}

National Cancer Institute. Idiopathic Right Bundle Branch Block by ECG Finding. NCI

Thesaurus. Code C71063.

An electrocardiographic finding of blocked cardiac electrical impulse conduction along the fibers of the right bundle branch that cannot be attributed to any cause. 